15 Shawe J, Mann S, Stephenson J. The move to integrated contraception and sexual health services: have we forgotten family 'planning'? J Fam Plann Reprod Health Care 2009; 35: 250-251.

16 Belfield T. Principles of contraceptive care: choice, acceptability and access. Best Pract Res Clin Obstet Gynaecol 2009; 23: $177-185$.

17 Dehlendorf C, Levy K, Ruskin R, Steinauer J. Health care providers' knowledge about contraceptive evidence: a barrier to quality family planning care? Contraception 2010 (in press) doi:10.1016/j.contraception.2009.11.006.

18 Glasier A, Scorer J, Bigrigg A. Attitudes of women in Scotland to contraception: a qualitative study to explore the acceptability of long-acting methods. J Fam Plann Reprod Health Care 2008; 34: 213-217.

19 Grimes DA. Forgettable contraception. Contraception 2009; 80: 497-499.

20 National Institute for Health and Clinical Excellence (NICE). Long-acting Reversible Contraception: The Effective and Appropriate Use of Long-acting Reversible Contraception (Clinical Guideline 30). London, UK: NICE, 2005.

21 Mullin N, Kirkman R. Coil or intrauterine device? Patient preferences for contraceptive terminology. J Fam Plann Reprod Health Care 2004; 30: 46-48.

22 Trussell J, Guthrie KA. Talking straight about emergency contraception. Contraception 2007; 33: 139-142.

\title{
"Sexual Pleasures": an evening seminar organised by the RSM Sexuality and Sexual Health Section, London, UK, 26 February 2010
}

\section{Susan Quilliam}

\section{Background}

Given that we work in a largely problem-led area, it is perhaps surprising to find a Royal Society of Medicine (RSM) seminar entitled "Sexual Pleasures". The session (the third of its kind), which aims to bridge the divide between medicine and gynaecology, is declared suitable for professionals from both arenas; the actual delegate listing for this one also included microbiologists, therapists, midwives, endocrinologists and sexologists, as well as a smattering of medical journalists from publications as diverse as Prima Baby Magazine and New Scientist.

\section{Female sexuality}

Following a welcome and brief introduction by the seminar's organiser, Dr Kevan Wylie (Clinical Lead, Porterbrook Clinic, Sheffield, UK), it wasn't long before attendees were shocked by Professor John Studd (Consultant Gynaecologist, Chelsea and Westminster Hospital, London, UK), whose presentation on 'Attitudes to Female Sexuality' centred on the disturbing revelation that in the 19th century so-called 'hysterical' symptoms as diverse as premenstrual syndrome, female masturbation and a desire for divorce were at one time treated by ovariotomy and clitoridectomy. Drawing on sources as diverse as medical history - Isaac Baker Brown and Marie Stopes - through to literature - H G Wells and Oscar Wilde - the presentation left the whole audience gasping at the brutality of such treatments, and the female portion of the audience incredibly grateful that they were born in the 20th century.

\section{Sex during pregnancy}

Next came Rachel Foux (Psychosexual Therapist and Director of Household Companion Ltd, UK), who highlighted the issue of sexual pleasure in pregnancy. Citing the worrying statistic that $70 \%$ of client sexual dysfunction in her practice seemed to begin after pregnancy and childbirth - but that most couples then waited 5 years before seeking help - Rachel went on to explore possible therapeutic and educational solutions. In particular she highlighted - and then debunked - several common myths that pregnant couples hold and that might prevent them from continuing their sexual relationship during (a healthy)

\section{J Fam Plann Reprod Health Care 2010; 36(2): 58}

\section{Cambridge, UK}

Susan Quilliam, BA, Cert Ed, MNLP, Freelance Writer, Broadcaster and Agony Aunt

Correspondence to: Ms Susan Quilliam.

E-mail: susan@susanquilliam.com pregnancy, such as that orgasm harms the fetus (truth: orgasm releases beneficial hormones) and that semen can induce premature labour (truth: only when the pregnancy is nearing term).

\section{STIs in MSM}

Dr Michael Waugh (Regional Sub-Dean for the Royal Society of Medicine - Northern and Yorkshire, Retired Consultant Genitourinary Physician, Leeds General Infirmary, Leeds, UK) then gave us a comprehensive introduction to the topic of sexually transmitted infections in men who have sex with men (MSM). From identifying several factors that, in today's sexualised society, make the whole issue even more worrying than before, he moved on to a definition of a 'good clinician' in this context. He then doubtless shocked a number of non-sexual health delegates with his coverage of the current fashion for barebacking (anal sex without a condom), and certainly turned a few nonmedical stomachs with his graphically detailed slides of sexually transmitted symptoms.

\section{Benefits of sexual intercourse}

Finally, Professor Stuart Brody (Professor of Psychology, University of the West of Scotland, Paisley, UK) summarised for us his controversial research that links penile/vaginal intercourse with emotional maturity and physical health, but suggests that masturbation and mutual masturbation don't convey the same benefits. He acknowledged early in his presentation - and with a wry smile - that his views might not receive instant acceptance given current beliefs about the importance of the clitoris. Yet in fact his case was carefully argued and, when in the question and answer session following the presentations he was challenged by delegates, he seemed consistently able to defend his conclusions. Shere Hite and her fans may well have to rethink.

\section{Concluding remarks}

As promised, the seminar was well balanced, useful in content and more than competent in presentation style. All in all, an informative, entertaining and inspirational event.

Should readers need any further encouragement to attend next year's "Sexual Pleasures" seminar, let me add two more practical motivators. First, the seminar is free to RSM Fellows, Associates and Student members and costs only between $£ 10$ and $£ 35$ for non-RSM members. [NB. You don't have to be an RSM member to attend their seminars or indeed to be on their e-mail list: http://www.rsm.ac.uk.]. Plus, the seminar carries two CPD credits. What's not to like? 